\title{
Drug-loaded Cellulose Acetate and Cellulose Acetate Butyrate Films as Ocular Inserts
}

\author{
S. NILAY, U.A. PATIL, B.M. DINESH* AND B. G. DESAI
}

Karnatak Lingayat Education Society's College of Pharmacy, II Block, Rajajinagar, Bangalore Karnataka, India-560010.

The purpose of this research work was to evaluate the contribution of formulation variables on release properties of matrix type ocular films containing chloramphenicol as a model drug. This study investigated the use of cellulose acetate and cellulose acetate butyrate as film-forming agents in development of ocular films. Formulation variables were concentration of polymer and plasticizer. Prepared films were evaluated for thickness, tensile strength, water vapor transmission rate and in vitro dissolution study. All formulations showed extended drug release over a period of 12 hours. The levels of polymer and plasticizer had a significant influence on the drug release in initial periods. Diffusion exponents of all formulations were less than 0.5 , which confirmed that drug release occurred without swelling of inserts. Water vapor transmission rate was influenced by concentration of plasticizer. The best formulation showed $81.26 \%$ drug release in vivo at the end of $12 \mathrm{~h}$ with cellulose acetate and $79.06 \%$ with cellulose acetate butyrate. The in vitroin vivo release correlation was evaluated and the regression coefficient was found to be 0.9767 and 0.9007 for cellulose acetate and cellulose acetate butyrate formulation, respectively indicating good correlation between the in vitro and in vivo drug release.

Key words: Ocular films, cellulose acetate, cellulose acetate butyrate, chloramphenicol

\section{INTRODUCTION}

Ophthalmic drug delivery is one of the most interesting and challenging endeavours faced by the pharmaceutical scientist. The anatomy, physiology and biochemistry of the eye render this organ exquisitely impervious to foreign substances. The development of newer, more sensitive diagnostic techniques and therapeutic agents render urgency to the development of successful ocular drug delivery systems.

Topical delivery into the conjunctival cul-de-sac is, by far, the most common route of ocular drug delivery. The topical application of ophthalmically active drugs to the eye is the most prescribed route of administration for the treatment of various ocular disorders. It is generally agreed that the intraocular bioavailability of topically applied drugs is extremely poor $[1,2]$. The conventional ocular dosage forms pose various constraints like short residence time, large drainage factor, frequent instillation and pulsed dosing of drug. The therapeutic efficacy of drug for ophthalmic use can be greatly improved by prolonging its contact with the corneal surface. Some of the newer, sensitive and successful ocular drug delivery systems like inserts, biodegradable polymeric systems and collagen shields are being developed in order to attain ocular bioavailability and sustained action of drugs.

Ocular inserts offer an attractive alternative approach to the difficult problem of prolonging pre-corneal drug residence time by providing a controlled release of the drug. They are composed of a polymeric support containing drug(s) incorporated as dispersion or solution in the polymeric support.

Chloramphenicol is a broad-spectrum antibiotic originally isolated from Streptomyces venezuelae. It is primarily bacteriostatic and acts by inhibition of protein synthesis by interfering with the transfer of activated amino acids from soluble RNA to ribosomes.

\footnotetext{
*Author to whom correspondence may be addressed.
} 
The aim of the research work was to formulate and evaluate sustained release ocular inserts using Cellulose Acetate (CA) and Cellulose Acetate Butyrate $(\mathrm{CAB})$ as polymeric films in view to sustain the release of drug in the eye cavity.

\section{MATERIALS AND METHODS}

\section{Materials}

Chloramphenicol was obtained as a gift sample from Ophthal Remedies (Surendranagar, India). Cellulose acetate and cellulose acetate butyrate were procured from Rolex Chemical Industries (Mumbai, India) while glycerin and dibutyl phthalate were obtained from S. D. Fine Chemicals Ltd. (Mumbai, India).

\section{Formulation of ocular films}

Cellulose acetate and cellulose acetate butyrate were used as film forming polymers in three different concentrations with dibutyl phthalate or glycerin as plasticizers in two different concentrations. Ocular films containing chloramphenicol were prepared by solvent casting technique using Anumbra $^{\circledR}$ petridish (Bharat Enterprises, New Delhi, India).
Cellulose acetate or cellulose acetate butyrate was dissolved in the required amount of acetone using a magnetic stirrer. The drug was dissolved separately in $2 \mathrm{ml}$ acetone and added to the polymeric solution. The plasticizer was added and stirred for $10 \mathrm{~min}$ using magnetic stirrer. The resulting solution was poured into Anumbra $^{\circledR}$ petridish of diameter $9 \mathrm{~cm}$. Evaporation of solvent was carried out in a controlled manner using an inverted funnel at room temperature for $24 \mathrm{~h}$. After complete drying, the prepared films were wrapped in aluminium foil and packed in air-tight bags till further use. Ocular films of $9 \mathrm{~mm}$ diameter containing $1 \mathrm{mg}$ chloramphenicol were cut using a cork borer at the time of use. Tables 1 and 2 outline the composition of the different formulations prepared using cellulose acetate and cellulose acetate butyrate respectively.

\section{Evaluation of ocular films}

Drug content uniformity: Ocular films of $9 \mathrm{~mm}$ diameter were kept in $10 \mathrm{ml}$ vials and equilibrated with $5 \mathrm{ml}$ isotonic sodium phosphate buffer ( $\mathrm{pH} 7.4$ ) for $24 \mathrm{~h}$. The vials were shaken at various intervals during this period. Samples were withdrawn, diluted

Table 1: Formulation composition for ocular films based on cellulose acetate

\begin{tabular}{lcccccc}
\hline Ingredients & A1 & A2 & A3 & A4 & A5 & A6 \\
\hline Cellulose acetate (mg) & 300 & 300 & 400 & 400 & 500 & 500 \\
Chloramphenicol (mg) & 96 & 96 & 96 & 96 & 96 & 96 \\
Glycerin* (\% w/w) & 30 & 40 & 30 & 40 & 30 & 40 \\
Acetone (ml) & 15 & 15 & 15 & 15 & 15 & 15 \\
\hline
\end{tabular}

*Plasticizer was used as percentage of dry weight of polymer.

Table 2: Formulation composition for ocular films based on cellulose acetate butyrate

\begin{tabular}{lcccccc}
\hline Ingredients & B1 & B2 & B3 & B4 & B5 & B6 \\
\hline Cellulose acetate butyrate (mg) & 400 & 400 & 500 & 500 & 600 & 600 \\
Chloramphenicol (mg) & 96 & 96 & 96 & 96 & 96 & 96 \\
Dibutyl phthalate* (\% w/w) & 30 & 40 & 30 & 40 & 30 & 40 \\
Chloroform (ml) & 13 & 13 & 13 & 13 & 13 & 13 \\
Acetone (ml) & 2 & 2 & 2 & 2 & 2 & 2 \\
\hline
\end{tabular}

*Plasticizer was used as percentage of dry weight of polymer. 
appropriately and assayed spectrophotometrically at $278 \mathrm{~nm}$ to determine the drug content. The readings were recorded in triplicate and the drug content expressed as mean \pm SD of three determinations.

Thickness: Thickness of each formulation was measured using Baker Digital Caliper (Baker Gauges India Pvt Limited, Pune, India) at five different points. Readings were recorded and mean thickness and standard deviation calculated.

Water vapor transmission study: The studies were carried out using $10 \mathrm{ml}$ vials containing $1 \mathrm{~g}$ of $\mathrm{CaCl}_{2}$. These vials were tightly covered with film formulation using an adhesive tape and kept in a desiccator maintained at $84 \%$ r.h. using a saturated $\mathrm{KCl}$ solution. The vials were weighed initially before placing in the desiccator and reweighed at $24 \mathrm{~h}$ intervals up to 7 days. Water vapor transmission rate was calculated using equation I:

Rate $=\frac{\text { Final weight }- \text { Initial weight }(\mathrm{mg})}{\text { Time }(\mathrm{h})} \ldots \ldots . . \mathrm{I}$

Tensile strength: The tensile strength was determined using films of $1 \mathrm{~cm}$ width and $4 \mathrm{~cm}$ length. The films were fixed onto the tensile strength apparatus (DigiSTRENGTH ${ }^{\mathrm{TM}}$, Paramount Instruments, Pvt Ltd, New Delhi, India) in such a way that the length of films between the jaws was initially $2 \mathrm{~cm}$. The distance travelled by the pointer in order to break the film $(\Delta \mathrm{L})$ and the weight required (break force) were noted. Tensile strength was calculated using equation II:

Tensile stength $=\frac{\text { Break force } \mathrm{x}(1+\Delta \mathrm{L} / \mathrm{L})}{\mathrm{a} \times \mathrm{b}} \ldots . \mathrm{II}$

Where:

$\mathrm{a}=$ width, $\mathrm{b}=$ thickness, $\mathrm{L}=$ length,$\Delta \mathrm{L}=$ elongation at break.

In-vitro dissolution study: Ocular films of $9 \mathrm{~mm}$ diameter were placed in a $100 \mathrm{ml}$ beaker containing $25 \mathrm{ml}$ isotonic sodium phosphate buffer ( $\mathrm{pH}$ 7.4). A wire net was placed over the film to prevent movement of the film. The beaker was placed on magnetic stirrer and the solution stirred vigorously. Samples were withdrawn after every hour for 12 hours and replaced with equal volumes of fresh buffer. The samples were analyzed for drug content against isotonic sodium phosphate buffer as a blank at wavelength of $278 \mathrm{~nm}$ using double beam UV visible spectrophotometer (Shimadzu 1700PC, Kyoto, Japan) .The drug release and \% drug release at the end of every hour was calculated from slope of the calibration standard curve. Figures 1 and 2 are plots of $\%$ drug release against time for $\mathrm{CA}$ and $\mathrm{CAB}$ formulations, respectively.

\section{Treatment of dissolution data with different release models}

To determine the mechanism of drug release from ocular films, the dissolution data obtained from the above experiments were treated to the different release kinetic models $[4,5]$ according to the following equations:

Zero order kinetics:

$$
\mathrm{Q}=\mathrm{K}_{0} \mathrm{t}
$$

Where $\mathrm{Q}$ is the amount of drug released and $\mathrm{K}_{0}$ is zero order release rate constant.

Higuchi's square root of time model:

$$
\mathrm{Q}=\mathrm{K}_{\mathrm{H}} \mathrm{t}^{1 / 2} \ldots \ldots \ldots \ldots \ldots \ldots \ldots \ldots . . . \ldots \ldots
$$

Where $\mathrm{Q}$ is the amount of drug released and $\mathrm{K}_{\mathrm{H}}$ is Higuchi release rate constant.

Korsmeyer and Peppas kinetics:

$$
\mathrm{F}=\left(\mathrm{M}_{\mathrm{t}} / \mathrm{M}_{\infty}\right)=\mathrm{K}_{\mathrm{m}} \mathrm{t}^{\mathrm{n}} \ldots \ldots \ldots \ldots \ldots \ldots \ldots \mathrm{V}
$$

where $M_{t}$ is drug release at time $t, M_{\infty}$ is total amount of drug in the formulation, $\mathrm{F}$ is fraction of drug release at time $t, K_{m}$ is constant dependent on geometry of dosage form and $n$ is diffusion exponent indicating the mechanism of drug release. For films, a value of $\mathrm{n}=0.5$ indicates Fickian diffusion, $\mathrm{n}=0.5-1.0$ indicates anomalous transport and $n=1.0$ indicates caseII transport. 


\section{Sterilization and test for sterility}

The optimized formulations from both systems (A3 and B5) were sterilized separately in their final package container by exposing them to UV radiation at $254 \mathrm{~nm}$ for $90 \mathrm{~min} \mathrm{[6].} \mathrm{The}$ irradiated ophthalmic inserts were tested for sterility according to the Indian Pharmacopoeia (IP) specifications [7]. The tests were carried out under aseptic conditions to avoid accidental contamination of the product during the test.

\section{In vivo studies}

In vivo studies were carried out after obtaining clearance from the Ethical Committee of K.L.E. Society's College of Pharmacy. Sterilized formulations A3 and B5 were selected for in vivo drug release study. Five male albino rabbits each weighing 2-2.5 kg were selected. The study was carried out by placing one insert of optimized formulation in the conjuctival cul-desac of the right eye and blank film in the conjunctival cul-de-sac of the left eye, which served as the control [8-9]. The ocular inserts were carefully removed after 1, 2, 3, 6 and $12 \mathrm{~h}$ and analyzed for drug content by UV spectrophotometry at $278 \mathrm{~nm}$. The drug content obtained was used to calculate the amount of drug released in the rabbit's eye. The studies were carried out in triplicate and results are expressed as mean $\pm \mathrm{SD}$.

The in vitro data and in vivo results obtained were correlated by plotting the in vitro drug release against in vivo drug release. The regression coefficient was calculated using Microsoft Excel ${ }^{\circledR}$.

\section{RESULTS AND DISCUSSION}

The results of thickness, water vapour transmission, tensile strength and drug content uniformity are shown in Table 3. The drug content range for formulations based on CA was 0.927-1.011 $\mathrm{mg}$ while that for CAB formulations was $0.964-1.003 \mathrm{mg}$. The standard deviation was found to be negligible thus establishing the content uniformity of the film produced. The maximum thickness observed was $0.126 \mathrm{~mm}$ and $0.124 \mathrm{~mm}$ for $\mathrm{CA}$ and $\mathrm{CAB}$ formulations, respectively, which is an acceptable limit as compared to similar products in the market. It was clearly seen that there was an increase in thickness with increase in polymer concentration of formulation. Formulations based on CA showed higher transmission rates than those based on CAB. The difference in water vapor transmission rate can be attributed to the difference in film porosity, which is known to vary depending on the type and concentration of plasticizers and film former used [10]. The results of tensile strength clearly indicate that $\mathrm{CAB}$ films were stronger and more flexible than CA films.

The dissolution profiles (Figures 1 and 2) show that there was retardation in drug release with increase in polymer concentration in both $\mathrm{CA}$ and $\mathrm{CAB}$ formulations. Formulation $\mathrm{A} 3$ exhibited a controlled drug release spread over $12 \mathrm{~h}$. Formulation A5 showed highest retardation, as it released $65 \%$ of drug by the end of $12 \mathrm{~h}$ which was not acceptable. The increase in plasticizer concentration showed increase in drug release initially. This may suggest that increasing plasticizer concentration may cause increase in film porosity and therefore increase the drug release. Similar observations of in vitro drug release were seen with $\mathrm{CAB}$ formulations, where $\mathrm{B} 2, \mathrm{~B} 4$ and $\mathrm{B} 6$ showed relatively higher drug release. Formulation B5 showed better drug release with only $22.44 \%$ drug being released at the end of 1 $\mathrm{h}$ and $73.57 \%$ drug being released at the end of $12 \mathrm{~h}$.

The dissolution data of different formulations is shown in Table 4. The dissolution of most formulations fitted well into the Higuchi model with regression coefficients that indicated the release of drug from the ocular films to be through a diffusion mechanism. The dissolution data were analyzed using Korsmeyer Peppas model. The values of diffusion coefficients were found to range from 0.29 to 0.45 for CA films and 0.18 to 0.47 for CAB films. Since values of diffusion exponent (n) were found to be less than 0.50 , the mechanism of drug release from films was characterized as Fickian diffusion [4]. 
Table 3: Evaluation of CA and CAB ocular films

\begin{tabular}{lcccc}
\hline Formulation & $\begin{array}{c}\text { Drug Content } \\
(\mathbf{m g})\end{array}$ & $\begin{array}{c}\text { Water vapour } \\
\text { transmission rate } \\
(\mathbf{m g} / \mathbf{h r})\end{array}$ & $\begin{array}{c}\text { Thickness } \\
(\mathbf{m m})\end{array}$ & $\begin{array}{c}\text { Tensile strength } \\
\left(\mathbf{k g} / \mathbf{m m}^{2}\right)\end{array}$ \\
\hline A1 & $0.981 \pm 0.037$ & $5.870 \pm 0.005$ & $0.066 \pm 0.005$ & 0.3169 \\
A2 & $0.965 \pm 0.013$ & $3.395 \pm 0.005$ & $0.074 \pm 0.005$ & 0.3491 \\
A3 & $1.011 \pm 0.033$ & $5.609 \pm 0.005$ & $0.100 \pm 0.007$ & 0.3438 \\
A4 & $0.927 \pm 0.005$ & $7.770 \pm 0.005$ & $0.102 \pm 0.004$ & 0.3466 \\
A5 & $0.979 \pm 0.083$ & $4.718 \pm 0.005$ & $0.114 \pm 0.005$ & 0.4305 \\
A6 & $0.980 \pm 0.031$ & $4.814 \pm 0.005$ & $0.126 \pm 0.005$ & 0.4466 \\
B1 & $0.964 \pm 0.026$ & $0.948 \pm 0.029$ & $0.074 \pm 0.005$ & 0.3111 \\
B2 & $0.982 \pm 0.036$ & $1.013 \pm 0.052$ & $0.078 \pm 0.005$ & 0.3714 \\
B3 & $0.989 \pm 0.032$ & $0.851 \pm 0.034$ & $0.108 \pm 0.004$ & 0.4292 \\
B4 & $0.998 \pm 0.027$ & $0.942 \pm 0.025$ & $0.118 \pm 0.004$ & 0.4934 \\
B5 & $0.996 \pm 0.025$ & $0.462 \pm 0.042$ & $0.124 \pm 0.005$ & 0.4166 \\
B6 & $1.003 \pm 0.016$ & $0.744 \pm 0.035$ & $0.124 \pm 0.005$ & 0.4675 \\
\hline
\end{tabular}

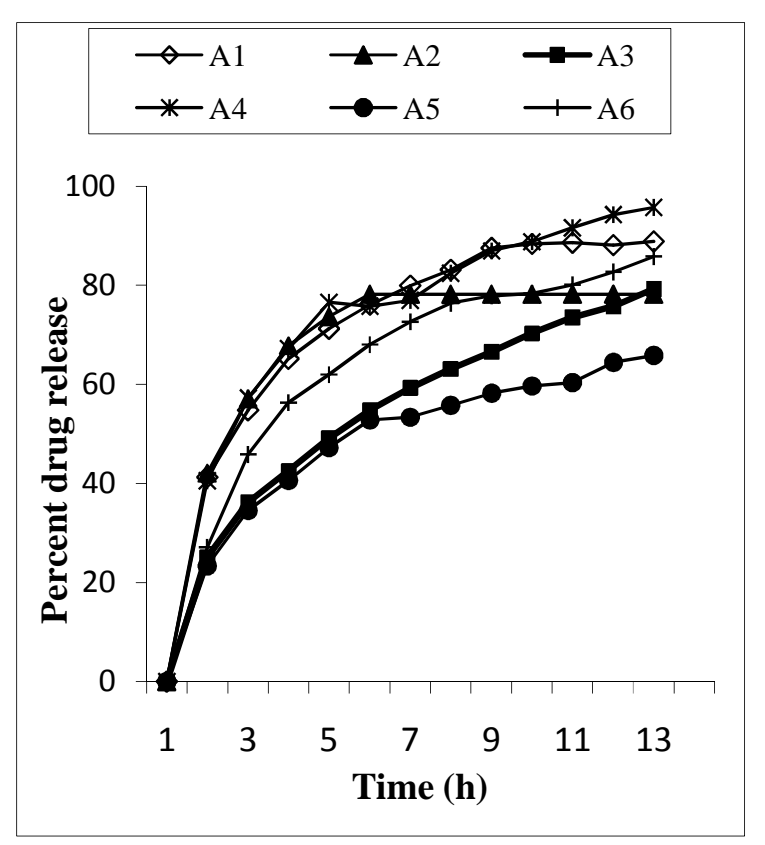

Figure 1: Dissolution profile of cellulose acetate formulations.

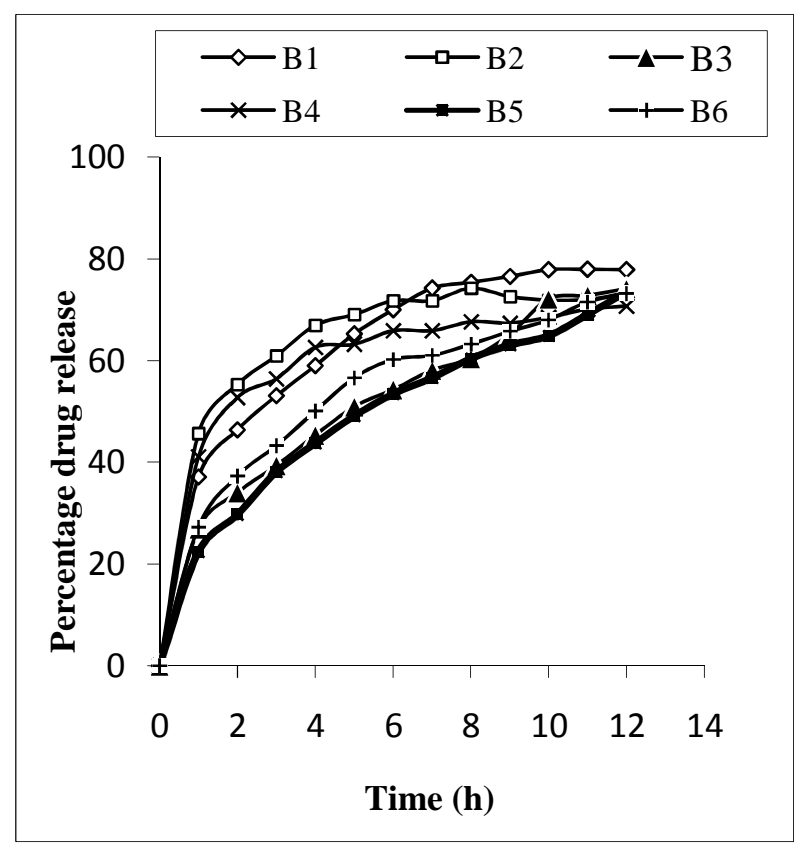

Figure 2: Dissolution profile of cellulose acetate butyrate formulations. 
Table 4: Dissolution data treatment of $\mathrm{CA}$ and $\mathrm{CAB}$ based formulations

\begin{tabular}{lccccccc}
\hline Batch & \multicolumn{2}{c}{$\begin{array}{c}\text { Zero order } \\
\text { Kinetics }\end{array}$} & \multicolumn{2}{c}{$\begin{array}{c}\text { Higuchi's } \\
\mathbf{t}^{1 / 2}\end{array}$} & \multicolumn{3}{c}{$\begin{array}{c}\text { Korsmeyer Peppas } \\
\text { Kinetics }\end{array}$} \\
\cline { 2 - 8 } & $\mathbf{K}_{\mathbf{0}}$ & $\mathbf{r}^{\mathbf{2}}$ & $\mathbf{K}_{\mathbf{H}}$ & $\mathbf{r}^{\mathbf{2}}$ & $\mathbf{n}$ & $\mathbf{r}^{\mathbf{2}}$ & $\mathbf{K}_{\mathbf{m}}$ \\
\hline A1 & 5.5599 & 0.7062 & 18.98 & 0.9223 & 0.3094 & 0.9627 & 1.6475 \\
A2 & 5.6492 & 0.7052 & 19.115 & 0.9228 & 0.3043 & 0.9615 & 1.6614 \\
A3 & 5.516 & 0.8874 & 21.59 & 0.9973 & 0.4543 & 0.9985 & 1.4138 \\
A4 & 5.461 & 0.6859 & 18.105 & 0.9099 & 0.2911 & 0.9462 & 1.6677 \\
A5 & 4.316 & 0.8002 & 16.053 & 0.9594 & 0.3953 & 0.9721 & 1.4088 \\
A6 & 5.694 & 0.7809 & 21.44 & 0.9302 & 0.4234 & 0.9395 & 1.5067 \\
B1 & 4.9958 & 0.7383 & 17.364 & 0.9452 & 0.3169 & 0.978 & 1.5792 \\
B2 & 3.7949 & 0.5227 & 10.145 & 0.8102 & 0.185 & 0.9041 & 1.6892 \\
B3 & 5.1739 & 0.8952 & 19.989 & 0.9932 & 0.4246 & 0.9923 & 1.4104 \\
B4 & 3.7247 & 0.5668 & 10.395 & 0.8811 & 0.1998 & 0.9368 & 1.6485 \\
B5 & 5.1134 & 0.9022 & 20.301 & 0.9962 & 0.4764 & 0.9971 & 1.3487 \\
B6 & 4.8447 & 0.8233 & 18.082 & 0.9786 & 0.3914 & 0.9890 & 1.4533 \\
\hline
\end{tabular}

The sterile inserts of A3 and B5 complied with the test for sterility as per the IP specifications. The results of in vivo studies showed $81.26 \%$ and $79.06 \%$ drug released at the end of $12 \mathrm{~h}$ for $\mathrm{CA}$ and $\mathrm{CAB}$ formulations respectively (Table 5). The in vitro-in vivo release correlation was carried out and the regression coefficient was found to be 0.9767 and 0.9007 for $\mathrm{CA}$ and $\mathrm{CAB}$ formulation respectively indicating good correlation between the in vitro and in vivo drug release. The stability studies indicated that there was no significant difference in drug content and percentage cumulative release initially and at the end of 6 weeks.

Table 5: In vivo drug release data of formulations A3 and B5

\begin{tabular}{lcccc}
\hline \multirow{2}{*}{ Time (h) } & \multicolumn{4}{c}{ \% Drug release } \\
\cline { 2 - 5 } & \multicolumn{3}{c}{ A3 } & \multicolumn{2}{c}{ B5 } \\
\cline { 2 - 5 } & In vitro & In vivo & In vitro & In vivo \\
\hline 1 & $25.28 \pm 4.75$ & $23.85 \pm 1.52$ & $22.44 \pm 0.77$ & $31.25 \pm 1.19$ \\
2 & $36.18 \pm 3.11$ & $38.44 \pm 1.71$ & $29.80 \pm 0.66$ & $51.00 \pm 2.81$ \\
3 & $42.63 \pm 5.02$ & $53.73 \pm 1.79$ & $38.13 \pm 1.03$ & $59.83 \pm 1.57$ \\
6 & $59.28 \pm 5.97$ & $67.79 \pm 2.48$ & $53.45 \pm 2.81$ & $66.08 \pm 2.48$ \\
12 & $79.26 \pm 4.84$ & $81.26 \pm 1.56$ & $73.57 \pm 2.97$ & $79.06 \pm 2.51$ \\
\hline
\end{tabular}

\section{CONCLUSION}

From the experiment conducted, it can be concluded that $\mathrm{CAB}$ and $\mathrm{CA}$ may be used as film forming agents especially for ocular drug delivery for better and sustained drug release. Both CA and CAB films showed good drug rel- ease for up to $12 \mathrm{~h}$ in selected formulations of chloramphenicol. From the evaluation results and appearance of films, it was found that $\mathrm{CAB}$ films were more suitable for designing drug loaded ocular inserts to provide sustained release of the drug in the ocular cavity. 


\section{REFERENCES}

[1] S.S. Chrai, M.C. Makoid, S.P. Erikson and J.R. Robinson. J. Pharm. Sci. 64 (1974) 333-338.

[2] S.S.Chrai and J.R.Robinson. J. Pharm. Sci. 63 (1974) 1218-1225.

[3] H. Sasaki, C. Tei, K. Nishida and J. Nakamura. J. Control Release 27(1993)127-137.

[4] P. Costa and M.S. Lobo. Eur. J. Pharm. Sci.13 (2001) 123-133.

[5] P.L. Ritger and N.A. Peppas. J. Control Release 5(1987) 37-42.
[6] P.M. Dandagi, F.V. Manvi, M.B. Patil, V.S. Mastiholimath and R. Rathod. Ind. J. Pharm. Sci. 66 (2004) 309-312.

[7] The Indian Pharmacopoeia Vol II., The Controller of Publications, New Delhi. 1996.

[8] R.D. Schoenwald and V.F. Smolen. J. Pharm. Sci. 60 (1971) 1039-1046.

[9] A. Zaffaroni, A.S. Michaels and F.Theeuwes. US Patent 4,036,227. 1977.

[10] J. Yuan, P.P. Shang and S.H. Wu. Pharm. Tech. Oct (2001) 62-73. 